give brief accounts of research projects covering a wide field including stroke, head injury, brain tumours and brain death. Basic haemodynamics as well as practical applications such as intraoperative monitoring are dealt with.

The volume is very much one for the specialist working in the field. It enables him or her to see what work is going on and the results being obtained. It would not be of interest to the general reader.

J MARSHALL

The Threatened Medical Identity of Psychiatry: The Winds of Change.

By THEODORE PEARLMAN. (Pp 270; Price: \$49.75) 1992 Illinois USA, Charles $C$ Thomas. ISBN 0-398-05768-0

The author grew up in South Africa and worked there as a general practitioner before specialising in psychiatry and emigrating to the United States. He has written a series of essays on the present practice of psychiatry principally in the country of his adoption. These range from a critique of DSM3 (a USA classification of psychiatric disorders) to excursions into psychopolitics (Russian and South African psychiatry).

The tone is informal, loosely structured and highly personal. Idiosyncratic assertions and dogmatic opinions abound. Dr Pearlman agonises over the state of psychiatry and diagnoses an identity crisis. He deplores the medicalisation of behavioural disorders and is equally scathing about the claims of dynamic psychotherapy and biological psychiatric research. Psychopharmacology fares little better. In his scheme of things the psychiatrist is a hospital based general physician with an interest in psychological disorders, at the ready to diagnose organic aetiologies underlying psychiatric syndromes and to advise on adverse psychological reactions to physical disease. He has little to say about the chronic psychoses other than a half-approving nod in the direction of Lang and Szasz. The practice of psychiatry in the community hardly merits a mention. $\mathrm{He}$ is rather better on some of the more bread and butter issues that face American psychiatry: the influence of health insurance on the quality of care; the territorial battles between psychiatrists and psychologists; and the increasing bureacratisation of medicine. This is very much one man's view of his own speciality and should be treated as such

Problems and Methods in Longitudinal Research: Stability and Change. Edited by: D MAGNUSSON, L R BERGMAN, G RUDINGER and B TÖESTAD (Pp 351; Price $\mathrm{H} / \mathrm{b} £ 55.00$; $\$ 100.00)$. 1991. Cambridge, University Press. ISBN 0-521-40195-X

This is a collection of papers which were read at a workshop organized by the European Network on Longitudinal Studies on Individual Development (ENLS) within the framework of the European Science Foundation. The book is the fifth of a series of volumes dealing with various methodological problems in longitudinal research; the present one concentrating on problems of statistical analysis and interpretation of data. In particular, the aim of the present volume is to illustrate an indispensible link between the correct method of data treatment and the explicit formulation of a substantive problem. With this aim, each chapter (written by different authors) sets out a particular problem and describes a particular approach to the solution of the problem. Presumably, in the workshop itself, there might have been discussion concerning alternative strategies for solving these particular problems, stressing relative strengths and weaknesses of the various statistical methodologies. This is completely missing from the book, however, and for this reason the book is rather unsatisfactory from the reviewer's point of view. There is very little link between the chapters and very little evidence of communication between the authors. For this reason the beginner in this area will not find this volume as useful as a well-written textbook. It is a book to dip into to see how a particular worker proposes to solve some particular challenge.

There are fifteen chapers. I found the later chapters the more interesting, starting with Chapter 7, by Pickles and Rutter, in which they discuss searches for 'turning points' in developmental processes. The chapter on the use of event history models in social mobility research (Blossfeld, Hamerle and Mayer) was also very useful. There were two chapters on modelling genetic effects in longitudinal research, but these are perhaps a little specialised for the general reader. Of more general interest is the chapter on structural equation modelling of intellectual development (Rudinger, Andres and Rietz) and one on latent structure models for discrete data (Anderson)

I do not think that I learnt a lot from scanning through the pages of this volume, however, except in the chapter by Shröder, Edelstein and Hoppe-Graff on qualitative analyses of individual differences in intraindividual change.

GRAHAM DUNN

\section{Current Trends in the Treatment of Par-} kinson's Disease

(Proceedings of the symposium on Current Trends in the Treatment of Parkinson's Disease held in Venice on 3-5th May 1991) Edited by yves aGID (Pp 106; Price $£ 18.00$ ) 1992. London, John Libbey \& Co Ltd. ISBN 0861963393

This volume is the proceedings of the symposium held in 1991 to coincide with the European launch of Pergolide. The introduction suggests that the book will help clinicians make up their minds on the use of L-dopa and dopamine agonists in the treatment of Parkinson's disease. There is, however, little new data, but significant lobbying designed to help anyone take sides on important issues such as is L-dopa really toxic and does its 'early use accelerate development of fluctuations? and the reverse: do agonists with or without some L-dopa, delay such complications or really have any neuroprotective qualities? L-dopa preparations have provided the staple treatment world-wide for two decades improving both quality and quantity of life. Perhaps we need a Dopa appreciation society to ensure that it is not found guilty before we have convincing evidence, particularly as polypharmacy has its intrinsic problems and the very long term effects of agonist therapy are not yet known.
Although disappointing in its proposed aims there are some worthwhile and informative chapters. Within the first section on cell mortality mechanisms, the group from Pisa gives an interesting review on MPTP toxicity and the possible involvement of excitatory amino acids, including some provocative comments questioning the importance of the mitochondrial defect, at least as an explanation for cell death. The next chapter brings up the question of dopamine neurotoxicity involving some well known proposed mechanisms though with little evidence that they are active in vivo, except under conditions of ischaemia. It is followed by a nice review by Olanow of the role of free radicals in Parkinson's disease and how they could interact with other mechanisms such as excitotoxic and mitochondrial defects. Walters reviews current therapeutic approaches and the theoretical background to both palliative and protective treatment, followed by Tolosa on current strategies for L-dopa, administration with comments on the unproven idea that controlled release formulations of L-dopa could be less toxic than conventional preparations. There are additional chapters describing the molecular biology of dopamine receptors and Lees reviews the current indications for apomorphine and possible future directions The book finishes with two chapters giving a summary of the clinical data on Pergolide and some practical experience from both Milan and Houston.

Although this book does not come up to its stated aims there are a number of well written and interesting chapters from leaders in the field.

A C WILLIAMS

Disorders of the Cervical Spine. Edited by: $M$ B CAMINS and $P$ F O'LEARY (Pp 628 Illustrated; Price: $£ 115.00)$. 1992. London, Williams \& Wilkins Ltd. ISBN 0-683-01401-3

This is a large volume devoted to all aspects of diseases of the cervical spine, the contributors being mainly neurosurgeons and orthopaedic surgeons. It is not, however, unduly biased towards detailed descriptions of operative techniques and starts with good discussions with biomechanics, clinical syndromes, radiological investigations and neurophysiological monitoring. The scope of later chapters is wide enough to include enigmatic conditions such as thoracic outlet syndrome, cervical angina, and dysphagia and vertebral artery compression attributed to spondylotic spurs.

The section on trauma is notably good and includes excellent chapters on the classification of injuries of the cervical spine, basic principles of treatment and the use of Halo vests in management. There is much of interest in other sections including a good account, from Japan, of ossification of the posterior common ligament and on the use of decompressive laminoplasty.

Though the editors have chosen their subjects and authors so as to provide a very comprehensive account of the cervical spine, they have managed to avoid, on the whole, overlap between chapters. References are variable both in quantity and in up to datedness. The reviewer was unable to find any reference to very high doses of methyl prednisolone now used in spinal injury. There 